\title{
İzole Sinyalize Kavşaklar için Çiçek Tozlaşma Algoritması Kullanılarak Devre Süresi Modellerinin Geliştirilmesi
}

\author{
Ali Payıdar AKGÜNGÖR, Sevim YAVUZ, Ersin KORKMAZ*, Erdem DOĞAN \\ Kırıkkale Üniversitesi, Mühendislik Fakültesi., İnşaat Mühendisliği Bölümü, 71451, Kırıkkale. \\ (ORCID: 0000-0003-0669-5715) (ORCID: 0000-0002-9262-7278) \\ (ORCID: 0000-0003-3725-164X) (ORCID: 0000-0001-7802-641X)
}

\begin{abstract}
$\ddot{\mathbf{O z}}$
Son zamanlarda nüfus ve ekonomideki büyüme karayollarında araç kullanımını arttırmakta, buna bağlı olarak da kavşakların kapasitesi yetersiz kalmaktadır. Kavşakların verimsiz çalışmasından dolayı gecikme, yakıt tüketimi, emisyon salınımı artarken sürücü davranışları da olumsuz etkilenmektedir. Kavşak geometrilerinin iyileştirilmesinin yanı sıra, optimum devre süresinin doğru tespiti ve sinyal sürelerinin düzenlenmesi ile de bu sorunların minimuma indirilebilmesi mümkün olmaktadır. Bu çalışmada Çiçek Tozlaşma Algoritması (ÇTA) kullanılarak optimum devre süresi modelleri geliştirilmiştir. Ayrıca en düşük gecikmeye sahip olan devre sürelerinin belirlenmesinde Diferansiyel Gelişim Algoritmasından (DGA) yararlanılmıştır. Kalibre edilen Webster modeline ilave olarak sabit eklenmiş Webster model formu ve üstel formda devre süresi modelleri geliştirilmiştir. VISSIM simülasyon programı ile elde edilen gecikme değerlerine göre geliştirilen bütün modeller Webster modeli ve VISTRO optimizasyon programı ile karşılaştırılmış ve önerilen modellerin istatistiksel olarak daha iyi performansa sahip olduğu görülmüştür. Bu modellerin özellikle yüksek trafik hacmine sahip trafik durumlarında yetersiz kalan Webster modelindeki eksiklikleri kapatarak alternatif bir devre süresi tahmin modeli olarak kullanılabileceği ön görülmektedir.
\end{abstract}

Anahtar kelimeler: Optimum devre süresi, VISTRO, VISSIM, çiçek tozlaşma algoritması.

\section{Development of Cycle Length Models using Flower Pollination Algorithm for Isolated Signalized Intersections}

\begin{abstract}
Recently, the growth in population and economy has increased the use of vehicles on highways and accordingly the capacity of the intersections is insufficient. Delay, fuel consumption and emissions are increased due to the inefficient operation of intersections, and driver behavior is adversely affected. In addition to improving intersection geometry, by correct determination of optimum cycle length and arrangement of signal times, it is possible to minimize these problems. In this study, optimum cycle length models have been developed by using Flower Pollination Algorithm (FPA). Additionally, Differential Evolution Algorithm has been used to determine the cycle length which has the minimum delay value for each traffic situation. In addition to the calibrated Webster model, Webster model with constant form and exponential form have been developed as cycle length models. All models developed according to the delay values obtained with the VISSIM simulation program were compared with the Webster model and the VISTRO optimization program and the proposed models were found to have statistically better performance. It has been seen that these models can be used as an alternative cycle length estimation model by defeating the deficiencies in Webster model which is insufficient especially in traffic situations with high traffic volume.
\end{abstract}

Keywords: Optimum cycle length, VISTRO, VISSIM, flower pollination algorithm.

\section{Giriş}

Günümüzde taşıt sayıları ve seyahat talebindeki hızlı artış yol kapasitelerinin yetersiz kalmasına ve başta kavşaklar olmak üzere trafiğin sıkışmasına neden olmaktadır. Kavşak performansının, geometrilerinde

*Sorumlu yazar: ersinkorkmaz@kku.edu.tr

Geliş Tarihi: 10.06.2020, Kabul Tarihi: 01.07.2020 
yapılan değişikliklerle arttırılabilmesi her zaman mümkün olmadığından genelde optimizasyon teknikleri kullanılarak sinyalizasyon sistemlerindeki düzenlemelerle kavşak performansının iyileştirilmesi üzerine çalışılmaktadır. Kavşaklarda kapasitenin arttırılmasında ve sinyalizasyondan kaynaklı gecikmelerin azaltılmasında devre süresinin etkili bir parametre olduğu bilinmektedir. $\mathrm{Bu}$ nedenle, optimum devre süresinin modellenmesi başta trafik mühendisleri olmak üzere birçok araştırmacının dikkatini çekmiş ve uzun yıllardan beri bir araştırma konusu olmuştur.

1958 yılında Webster [1] tarafından geliştirilen gecikme bağıntısı ve minimum gecikmeye dayalı optimum devre süresi modeli kavşak kontrolünde ve devre süresinin tayininde yapılan ilk çalışmalardandır. Özellikle doygun altı trafik durumlarında etkili bir performansa sahip olan model, doygun üstü trafik durumlarında etkisini yitirmektedir. Thomas ve Uphurch 1998 yılında yaptıkları çalışmada trafik hacimlerinin ve optimum olmayan devre sürelerinin gecikme üzerindeki etkilerini incelemişler ve devre süresi, trafik hacmi gibi parametrelerin belirgin oranda artmasıyla gecikmenin de çok fazla arttığını ortaya koymuşlardır [2]. Webster'in optimum devre süresi modelinde devre süresi tahmininin yüksek olmasının nedenini bulmayı amaçlayan Cheng ve arkadaşları 2003 yılında Synchro 5 ve Highway Capacity Software (HCS) yazılımı kullanarak üç farklı devre süresi tahmin modeli geliştirmişlerdir. Yüksek trafik hacmi durumlarında üstel formdaki modelin diğer modellere oranla ve Webster' e kıyasla optimum devre süresini daha iyi tahmin ettiğini gözlemlemişlerdir. 2004 yılında Lan minimum gecikmeye dayalı olarak doğrusal olmayan regresyon analizi yöntemi kullanmıştır. $\mathrm{Bu}$ yöntemle kavşak kritik akım oranı, toplam kayıp süre ve analiz süresini içeren trafik akım parametreleri ve optimum devre süreleri arasındaki fonksiyonel ilişkiyi ortaya koymuştur [3]. Cheng ve arkadaşları 2005 yılında Webster devre süresi modelini geliştirerek ve üstel formda model oluşturarak farklı devre süresi tahmin modelleri önermişlerdir [4]. Farklı hacim ve kayıp zamanlarına göre CORSIM simülasyon programı üzerinden modellerin sonuçlarını Highway Capacity Manual (HCM) 2000 sonuçlarıyla karşılaştırmışlardır. Devre süresinin etkinliği ve verimliliğini değerlendirmeyi amaçlayan Day ve arkadaşları 2009 yılında Webster modeli ve HCM'in hesaplamalarını kullanarak devre süresi az, çok ve yeterli olduğunda sinyalize bir kavşaktaki devre süresinin etkinliğini araştırmışlardır [5].

2009 yılında kavşaklardaki trafik performansını optimuma yakın sağlamayı hedefleyen Singh ve arkadaşları genetik algoritma kullanarak gerçek zamanlı trafik sinyal kontrolü stratejisi uygulamışlardır [6]. Sinyalize kavşaklarda araç gecikmesini minimuma indiren optimum devre süresini bulmay1 amaçlayan Al- Kubaisi 2012 yılında sinyalize kavşakta araç davranışı için geliştirilen simülasyon modelinin uygulanmasına bağlı olarak bir regresyon modeli geliştirmiştir [7]. Geliştirdiği modelin çıktısını doğrulamak için OSCADY/3 yazılım paketi kullanmış ve sonuçların uyumlu olduğunu ifade etmiştir. Bağdat şehrindeki bir kavşak verilerine göre elde edilen devre süresi ve gecikme değerleriyle önerilen modelin sonuçlarını karşılaştırmış ve daha düşük gecikme ve devre süresinin elde edilebildiğini göstermiştir. 2012 yılında Sun ve arkadaşları devre süresi optimizasyonunu kullanarak sinyal kontrol sistemi geliştirmişlerdir. VISSIM simülasyon yazılımı ile doğrusal kontrol sisteminin kavşağın trafik kapasitesini arttırdığını ve kavşaktaki gecikmeyi azalttığını gösteren optimizasyon öncesi ve sonrasında karşılaştırmalar yapmışlardır [8]. Trafikteki gecikmeyi azaltmayı ve kapasiteyi artırmayı amaçlayan Dai ve arkadaşları 2013 yılında farklı trafik akımlarına göre ve ortalama saatlik trafik hacmine dayanarak önerdikleri basit ve pratik bir kavşak kontrol yöntemi ile kavşağın devre süresini hesaplamışlardır [9]. Sonuçları diğer yöntemlerle karşılaştırmışlar ve uyumlu olduğunu göstermişlerdir. 2013 yılında Dell'Orco ve arkadaşları trafik sinyal süresini optimize etmek için Harmoni Arama Algoritmasını kullanmışlardır [10]. Denge ağı tasarım problemini çözen bu çalışmada harmoni arama algoritmasına göre sinyal süresi optimizasyonu yapılmıştır. Geliştirilen model orta ölçekli bir yol ağı üzerinde test edilmiş ve sonuçlar önerilen metodun oldukça basit ve verimli olduğunu göstermiştir. Çin'de sinyalize kavşaklar için optimizasyona dayalı bir devre süresi modeli geliştirmeyi ve modelin etkilerini değerlendirmeyi amaçlayan $\mathrm{Wu}$ ve arkadaşları 2015 yılında Çin'in en büyük şehirlerinden biri olan Xi'an da 50 sinyalize kavşaktan trafik verileri toplamışlardır [11]. Optimum devre süresi için Webster'in gecikme modeli Çin trafik koşullarında yeniden kalibre edilmiştir. Önerilen optimize edilmiş devre süresi modelinin etkisini değerlendirmek için VISSIM simülasyon programı kullanılmış ve üç sinyalize kavşak üzerinden karşılaştırma yapılmıştır. Optimize edilmiş devre süresi modeli Transport and Road Research Laboratory (TRRL) modeline göre daha düşük gecikme ve devre süresini ortaya koymuştur. 2015 yılında Webster yönteminin gecikmeyi gerçek anlamda ne kadar temsil ettiğini belirlemek isteyen Murat ve Çakıcı çalışmalarında önce Webster'in optimum devre süresi modeli kullanarak oluşturduğu 14 senaryonun optimum devre süresi ve gecikmelerini hesaplamışlardır. Sonraki aşamada ise sezgisel 
optimizasyon yöntemlerinden harmoni araması, diferansiyel gelişim ve parçacık sürü optimizasyonu kullanarak yeniden optimum devre süresi ve gecikmeleri hesaplamışlar ve Webster'e göre daha iyi sonuçlar elde etmişlerdir [12]. 2016 y1lında Zakariya ve Rabia Kanada Kapasite Rehberinde ve Otoyol Kapasite Kılavuzunda kullanılan zamana bağlı gecikme modellerine göre minimum gecikmeyi veren optimum devre süresini tayin etmek için iki regresyon bağıntısı önermişlerdir. Bu regresyon bağıntısında gerekli verileri elde etmek ve optimum devre süresini saptamak için arama algoritması geliştirmişlerdir [13]. Sonuç olarak önerilen bağıntıların Webster modeline kıyasla yüksek trafik hacimlerinde optimum devre süresini daha iyi tahmin ettiğini görmüşlerdir. Jovanovic ve arkadaşları 2017 yılında arı kolonisi algoritmasına dayalı bir yaklaşımla sinyalize kavşaklar boyunca toplam seyahat süresini minimize edecek şekilde devre süresinin, devre süreleri arası zamanın (ofset) ve faz başına düşen sürenin belirlenmesini sağlamışlardır [14].

$\mathrm{Bu}$ çalışmada, meta sezgisel algoritmalar kullanarak farklı trafik durumlarını yönetebilen ve daha iyi performanslara sahip optimum devre süresi tahmin modellerinin geliştirilmesi amaçlanmıştır. Bunun için farklı kayıp sürelerine göre her trafik durumu için minimum gecikmeyi verecek devre süresinin diferansiyel gelişim algoritması ile araştırılması sağlanmış ve optimum devre süresi modelleri çiçek tozlaşma algoritması yardımıyla da geliştirilmiştir. ÇTA yaklaşımının bu konuda ilk defa uygulanması çalışmanın yeniliğini ortaya koymakta olup, güncel ve etkili performansa sahip olan bu yaklaşımının optimum devre süresinde uygulanabilirliğini de göstermektedir. Kullanılan algoritmalar ile VISSIM simülasyon programı ve VISTRO optimizasyon modülü bir sonraki bölümde detaylı olarak açıklanmış olup geliştirilen model formları bu bölümün sonunda verilmiştir. Modellerin performansları Webster modeli ve VISTRO optimizasyon programı sonuçları ile karşılaştırılarak bulgular ve tartışmanın yer aldığı 3. bölümde incelenmiş ve son bölümde ise çalışmadan elde edilen sonuçlar sunulmuştur.

\section{Materyal ve Metot}

Yapılan bu çalışmada Diferansiyel Gelişim Algoritması (DGA) kullanılarak bir arama algoritması oluşturulmuş ve üç kollu bir sinyalize kavşakta 266 farklı trafik durumu için gecikme değerini minimum yapan optimum devre süreleri elde edilmiştir. Elde edilen optimum devre süreleri kullanılarak Çiçek Tozlaşma Algoritması (ÇTA) yardımı farklı formlarda optimum devre süresi tahmin modelleri geliştirilmiştir. VISTRO optimizasyon programı geliştirilen modellerin performansları karşılaştırmak için kullanılmış olup VISSIM simülasyon programı ile simülasyonları gerçekleştirilmiş ve gecikme değerleri ortaya konulmuştur.

\subsection{Diferansiyel Gelişim Algoritması}

Popülasyon temelli sezgisel bir optimizasyon tekniği olan diferansiyel gelişim algoritması, Rainer Storn ve Kenneth Price tarafindan ortaya atılan işleyiş ve operatörleri itibariyle genetik algoritmayla (GA) benzerlik gösteren bir optimizasyon tekniğidir [15]. GA da kullanılan çaprazlama ve mutasyon işlemleri ayr1 ayrı gerçekleştirildiği için genetik algoritmada optimizasyon için uzun zamana ihtiyaç duyulmaktadır. DGA ile gelişime dayalı bir strateji önerilerek bu dezavantajın giderilmesi sağlanmıştır.

DGA'yı GA'dan ayıran en önemli fark ise mutasyon operatöründe olmaktadır. DGA'nın rastgele seçilmiş vektörlerin farkına dayanan bir mutasyon işlemi gerçekleştirmesi bu operatörü adaptif hale getirmektedir. Bu farklar uygun bir adım boyutu için önemli bir göstergedir. Çünkü, algoritma olarak optimum değişimlere doğru atılacak adım boyutu belirlenmesi önemli olup mutasyon operatörünün adaptif olmasından dolayı da algoritmanın performansını geliştirmekte ve güçlü yapmaktadır. Bu sayede popülasyon üyeleri arasındaki varyans arttı̆̆ında ya da azaldığında DGA'daki adım boyutu da buna göre değişmektedir. Ayrıca DGA yaklaşımında operatörlerin bütün popülasyona uygulanmaması, az satır ile kodlanması gibi avantajları algoritmanın tercih edilirliğini arttırmaktadır. DGA'nın diğer sezgisel yöntemlere göre diğer bir üstünlüğü de çok az parametre ile kontrol edilebilmesidir. Sadece 3 tane kontrol parametresi vardır ki bunlar mutasyon katsayısı F, çaprazlama katsayısı CR ve popülasyon büyüklüğüdür NP'dir. 4 temel operatör ile optimizasyonu gerçekleştiren DGA yaklaşımının temel adımları Şekil 1'de verilmektedir. 


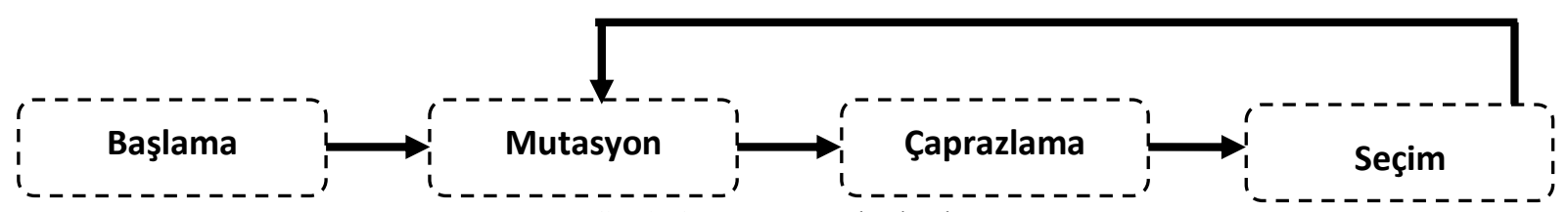

Şekil 1. DGA temel adımları

Her algoritmada olduğu gibi DGA içinde başlangıç popülasyonun doğru şekilde oluşturulması algoritmanın performansında önemli bir yere sahiptir. Optimum popülasyon hakkında önceden bir bilgi yok ise genellikle başlangıç popülasyonu her bir parametrenin belirlenen alt ve üst sınırları dahilinde rastgele olarak elde edilir. Eğer optimum popülasyon biliniyorsa bu bilgiyi kullanmak önemlidir. Böylece çözüm uzayı daraltılabilir ve optimum çözüm popülasyon oluşturulabilir. Mutasyon işleminde fark vektörünün kullanılması algoritmanın hızlı bir şekilde çözüme ulaşmasını sağlamaktadır. Farklı mutasyon stratejileri kullanılabilen bu yaklaşımda 1 ya da 2 tane fark vektörünün kullanılması ile mutasyon işlemi sağlanabilmektedir. Farklı mutasyon stratejileri /x/y/z şeklinde ifade edilmektedir. Burada $\mathrm{x}$ mutant vektörü oluşturmak için kullanılan baz vektörü, y mutasyon işleminde kullanılan fark vektörünün sayısını ve $\mathrm{z}$ de çaprazlama işleminde kullanılan çaprazlama şemasını ifade eder. X ile ifade edilen baz vektörü seçerken kullanılan yöntemler "rand, best, rand to best, current ve current to best and current to rand" olarak kullanılmaktadır. Çaprazlama işleminde ise üç farklı metottan birisi ile çaprazlama katsayısı belirlenir. Kullanılan katsayı, deneme vektörünün ne kadar mutant ve hedef vektörüne yakın olacağı üzerinde etkilidir. Eğer deneme vektörü mutant vektörüne yakınsa daha büyük adım boyutu uygulanır ve algoritma daha hızlı çalışır. Çaprazlamada kullanılan metotlar iki terimli (Binomial), üstel (exponential), aritmetiktir. Son operatörde ise yeni jenerasyonun oluşturulması gerçekleşir. DGA'da bu olay iki adaylı bir turnuva olarak da adlandırılabilir. Uygunluk fonksiyonunu mininize edecek şekilde deneme vektörü ile hedef vektörü arasında en iyi seçimi yaparak yeni jenerasyonu oluşturmaktır.

\section{2. Çiçek Tozlaşma Algoritması}

Karmaşık yapıya sahip pek çok problemin analitik yöntemler ile çözüme kavuşturulamamasından araştırmacılar farklı yaklaşımlara yönelmişlerdir. En kısa sürede en iyi sonuca ulaşmak için sezgisel ve meta sezgisel optimizasyon yöntemleri birçok probleme uygulanmıştır. Bu süreçte evrimdeki çiçeklerin amacının türün hayatta kalması, sayı ve nitelik açısından en uygun popülasyonun üretilmesi olduğu kanısından yola çıkılarak 2012 yılında Xin-She Yang tarafindan Çiçek Tozlaşma Algoritması (ÇTA) ortaya konulmuştur [16]. Doğanın bu ilginç işleyişinden ilham alınarak ortaya konan bu algoritma meta sezgisel yöntemlerden birisi olup, temel olarak çiçekli bitkilerin ürüme sürecinden ilham alınmıştır. Ortaya konulduğu günden beri hızlı bir şekilde popülaritesini arttıran bir algoritma olmuş ve farklı alanlardaki birçok araştırmacının dikkatini çekmiştir. Farklı alanlardaki uygulamaları ve mevcut yapay zekâ yaklaşımları ile performans kıyaslamalarında rekabet edici özelliklere sahip olduğu ve üstünlük gösteren sonuçları ortaya koymuştur. Yaklaşımın daha geniş çözüm uzayında arama yapması, az parametre ile kontrol edilebilmesi ve diğer meta-sezgisel yaklaşımlardan daha hızlı yakınsamaya sahip olması gibi üstünlükleri diğer yaklaşımlara göre daha çok tercih edilen bir algoritma olmasına neden olmaktadır.

Çiçek tozlaşmasında asıl amaç, en uygun canlılığın ve optimum biyolojik üreme evresinin sağlanmasıdır. Polenleşme işlemi biyotik ve abiyotik olmak üzere iki farklı tipte gerçekleşmektedir. Tüm türlerin \%90'ına yakını polenleşmede biyotik yöntemi kullanıp ve üremeyi sağlayıcı polenler kuşlar böcekler gibi hayvanlar yardımı ile taşınarak üreme işlemi gerçekleştirirken, \%10 oranında herhangi bir tozlaştırıcı olmadan abiyotik üreme gerçekleştirirler. Geri kalan çiçeklerde üremek için rüzgâr ve sudaki difüzyon gibi doğal olayları kullanmaktadır. Polenleme çaprazlama (cross) veya kendi kendine (self) olmak üzere iki farklı şekilde gerçekleşmektedir. Çapraz polenlemede farklı tür çiçeklerden gelen polenler kullanılırken, kendi kendine polenlemede bitki kendisinin ürettiği poleni ya da aynı türden faklı bir çiçekten polen kullanılmaktadır. Biyotik polenleme uzak mesafelerde bulunan kaynaklardan arılar, sinek, kuşlar gibi doğal taşıyıcılar kullanılarak gerçekleşebilir. Bu işlem küresel (global) bir işlem olmakla beraber yapılan araştırmalarla taşıyıcıların hareket karakteristiği Levy uçuşuna benzerlik göstermektedir. Aşağıdaki 4 temel kural kullanılarak mühendislik problemlerinin çözümü için çiçek polenleme algoritması geliştirilmiştir. 
Bu kurallar;

- Biyotik ve çaprazlama polenleme işlemi taşıyıcıların Levy uçuşuna uygun şekilde davranarak gerçekleştirilen küresel polenleme işlemidir

- Abiyotik ve kendiliğinden gerçekleşen polenleme işlemi yerel polenleme işlemi olarak kabul edilmektedir.

- Çiçek sabiti adı verilen katsayı üretim olasılığı olarak ifade edilir ve çiçek türlerinin benzerliği ile orantılı olarak değişirmektedir.

- Yerel ve global polenleme işlemi [0-1] aralığında belirlenen geçiş olasılığ değişkeni ile kontrol edilir.

Gerçek durumda her bir türün birden fazla çiçeği ve her bir çiçeğin milyarlarca polen gameti bulunmasına rağmen algoritma oluşturulurken kolaylık olması açısından her türün tek çiçeği ve her çiçeğin tek bir polen gameti ürettiği varsayımı kabul edilmiştir. Bu sayede polenleri ayrı ayrı ifade etme ve belirleme zorunluluğu ortadan kalkmıştır.

Çiçek sabitinin matematiksel ifadesi Denklem 1'de gösterilmiştir.

$x^{t+1}=x_{i}^{t}+\gamma L(\lambda)\left(g_{*}-x_{i}^{t}\right)$

Burada $x^{t+1}$ çözüm vektörü, $g^{*}$ mevcut en iyidir. $\gamma$ adım boyutunu ayarlama faktörüdür.

Levy dağıtımı tozlaşma kuvvetini karşılamak için kullanılır. Böcekler uzun mesafeli seyahat ederken, böceklerin hareketi Levy dağılımına göre gösterilebilir. Levy'nin matematiksel ifadesi Denklem 2'de gösterilmiştir.

$L \sim \frac{\lambda \Gamma(\lambda) \sin \left(\frac{\pi \lambda}{2}\right)}{\pi} \frac{1}{s^{1+\lambda}},\left(s \gg s_{0}>0\right)$

Burada $\Gamma(\lambda)$ standart gama fonksiyonudur ve s adım büyüklüğündedir. Bu dağılım $s>0$ büyük adımlar için geçerlidir. Teoride, $s_{0} » 0$ gereklidir, ancak uygulamada $s_{0} 0.1$ kadar küçük olabilir.

Yerel tozlanma için, hem Kural 2 hem Kural 3, Denklem 3'de gösterilmiştir.

$x^{t+1}=x_{i}^{t}+\epsilon\left(x_{j}^{t}-x_{k}^{t}\right)$

Burada $x_{j}^{t}$ ve $x_{k}^{t}$ aynı bitki türlerinin farklı çiçeklerinden gelen polen türüdür.

$\mathrm{Bu}$ algoritmanın dikkat çeken özelliği Levy dağılımını kullanarak arama uzayında birçok çözüm noktasının araştırılmasıdır. Global aramayla çözüm uzayında çözüm noktalarının belirlenmesi ve lokal arama vasıtasıyla çözüm noktalarının komşuluğunun araştırılması algoritmanın optimizasyon mantı̆̆ını oluşturmaktadır.

\subsection{VISSIM Simulasyon Programı ve VISTRO Optimizasyon Modülü}

PTV GmbH tarafindan geliştirilen VISSIM (Verkehr in Städten-Simulation: Traffic in TownsSimulation) hem şehirlerin gerçekçi bir şekilde modellenmesi hem de yayaların ve trafiğin modellenmesini amaç edinen zamana dayalı mikroskobik bir simülasyon programıdır. Toplu taşımalarında modellenebildiği bu sistemde trafiğin nasıl aktığı görsel olarak da simülasyon ortamında izlenebilmektedir. $\mathrm{Bu}$ programın kalibrasyon işlemi Karlsruhe Teknik Üniversitesi tarafindan yapılmışırı [17].

VISSIM, kullanılan diğer simülasyon programlarına göre pek çok imkan sağlamaktadır. Örneğin; bütün simülasyon boyunca kontrol parametreleri ile trafiğin hareketleri hakkında bilgi verir ve an an izlenir ve günümüzdeki trafikteki detektörlerden elde edilen mikroskobik akım ile ilgili parametreleri bilgisayar ortamında üretebilmektedir. Şehir içi ve şehirlerarası trafiği pek çok farklı yol yapılandırmaları ile ışıklı trafik işaretleri, duraklar gibi çeşitli durumlara göre analiz yapabileceğinden dolayı şehir içi trafik durumlarında yapılacak kontroller ve düzenlemelerin performanslarını görebilmek adına kullanılabilecek önemli programlardan biridir.

VISSIM'in uygulama alanlarından bazıları aşağıda sıralanmıştır.

- Aktif olan trafiğin yönetilmesi 
- Kapasitede yaşanan değişimlerden dolayı analiz yapılması

- Var olan ulaşımı geliştirilmesi

- Yol ayrımı olan yerlerin düzenlenmesi

- Toplu taşıma düzeni ve simülasyonudur.

VISSIM, trafiğin şerit değiştirme, seyirde yapılan değişiklikler gibi durumları ayarlayabilme imkanı verirken aynı zamanda da birden çok şerit içeren bir yolda taşıt davranışı ile birlikte hem aynı şeritte birbirini takip eden taşıtların birbirlerine olan etkilerini hem de yan şeritteki komşu taşıtların etkilerini de göz önüne alır. Simülasyon, sinyalize olarak kontrol edilen bir kavşağa gelen taşıtın dur çizgisine 100 metre mesafeden daha az bir uzaklık kaldığında taşıtın başka bir şeride geçmesine müsaade eder. Böylece, gerçek hayatta tek bir şeritte uzunca kuyrukların oluşması gibi gerçekçi olmayan bir durumun simülasyonda da gerçekleşmesi önlenir. Sürücü ve taşıt biriminin davranışı VISSIM'de ele alınan konulardan biridir. Bu davranışlar hem sürücünün kendi kişisel davranışına hem de taşıt kapasitesi denilen parametreye bağlıdır. Sürücü ve taşıt biriminin davranışsal özelliklerini tespit etmek amacıyla her bir sürücü-taşıt birimine özgü üç grup şeklinde gösterilen faktörlere nazaran değerlendirir [17].

VISTRO modulü kavşak hizmet düzeyini belirleme, sinyal süre optimizasyonu, trafik etki analizi, çoklu senaryoları yönetme ve kapsamlı raporlar oluşturma kabiliyetlerine sahip yazılımdır. Gecikmeyi minimum yapmayı amaçlayarak kavşak hizmet düzeyini yükseltebilecek şekilde sinyal sürelerinin optimizasyonu gerçekleștirebilen bu yazılım VISSIM programı ile entegreli olarak çalışabilmektedir. Ayrıca bünyesinde ulaşım ana planlarının hazırlanması, trafik koridorlarında gelecek iyileştirme ihtiyaçlarının değerlendirilmesi gibi farklı amaçlara yönelik de kullanım olanaklarını bulundurmaktadır.

\subsection{Modellerin Geliştirilmesi}

Optimum devre süresi tahmin modellerinin geliştirilmesinde DGA ve ÇTA olmak üzere iki farklı yöntem kullanılmıştır. DGA yaklaşımına dayalı olarak geliştirilen arama algoritmasında her bir trafik durumu için optimum devre süreleri elde edilmiştir. ÇTA yaklaşımında ise geliştirilen model formlarının optimizasyonu gerçekleştirilerek optimum devre süresi modelleri geliştirilmiştir. Zamana bağlı gecikme modellerinden birisi olan yolların kapasite kullanım rehberindeki (Highway Capacity Manual HCM) gecikme modeline göre Şekil 2'de gösterilen 3 kollu bir kavşağın farklı trafik durumları için en düşük gecikmeyi verecek devre süresinin araştırılması için bir arama algoritması oluşturulmuştur.

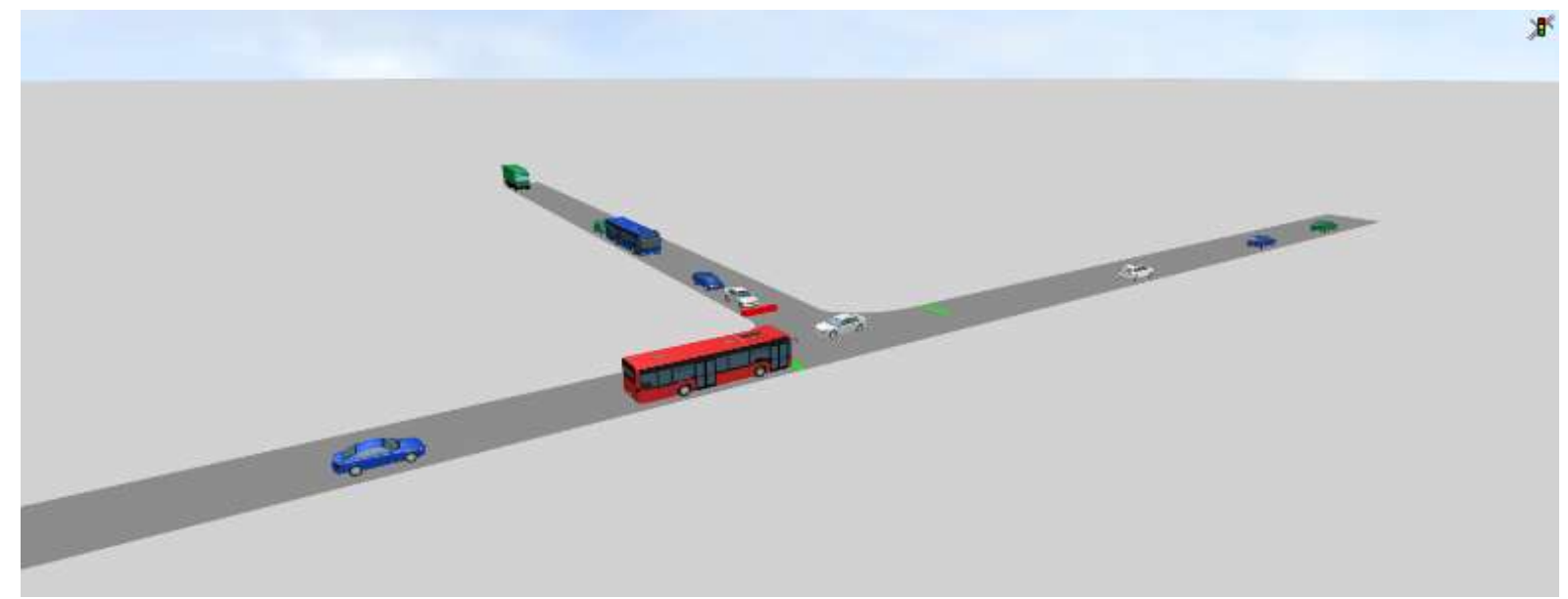

Şekil 2. Kavşak geometrisi

HCM gecikme bağıntısı Denklem 4'te yer almakta olup, bu bağıntının bileşenleri olan üniform gecikme ve eklenik gecikme bağıntıları sırasıyla Denklem 5 ve 6'da verilmiştir. Oluşturulan arama algoritmasında DGA yaklaşımı kullanılmış olup, araç başına düşen gecikmeyi minimum yapan değer amaç fonksiyonu olarak belirlenmiştir. Amaç fonksiyonunun ifadesi ise Denklem 7 'te verilmiştir.

$d=d_{1} *(P F)+d_{2}+d_{3}$

$d$ : Her bir araç için kontrol gecikmesi (saniye/araç) 
$d_{1}$ : Üniform kontrol gecikmesi (saniye/araç)

$P F$ : İlerleme Düzeltme Faktörü

$d_{2}$ : Eklenik gecikme (saniye/araç)

$d_{3}$ : Başlangıçta oluşan kuyruklanma gecikmesi (saniye/araç)

$d_{1}=\frac{0,5 * C *\left(1-\frac{g}{C}\right)^{2}}{1-\left[\min (1, \mathrm{X}) * \frac{g}{C}\right]}$

$C$ : Devre süresi (saniye)

$g$ : Efektif yeşil süre (saniye)

$\mathrm{X}$ : Akımın doygunluk derecesi $(\vartheta / c$ oranı)

$d_{2}=900 * T *\left[(X-1)+\sqrt{(X-1)^{2}+\frac{8 * k * I * X}{c * T}}\right.$

$T$ : Analiz edilen süre (saniye)

$k$ : Artan gecikme faktörü

I: Ölçüm düzeltme faktörü

$c$ : Kapasite (araç/saat)

Denklem 4'de verilen gecikme formülündeki $d_{3}$ gecikme değeri başlangıçta kavşakta bulunan gecikmeyi ifade eder. Eğer başlangıçta herhangi bir kuyruklanma yoksa bu değer sıfır olarak alınır.

$\operatorname{Min} F(x)=\sum_{n=1}^{m} \frac{D_{n}}{q_{n}}$

$D_{n}:$ Koldaki gecikme değeri

$q_{n}$ : Koldaki trafik akımı

$m$ : Kavşaktaki toplam kol sayısı

3 kollu olarak oluşturulan sinyalize kavşakta farklı trafik durumlarının elde edilmesi için trafik hacimleri $180 \mathrm{araç/saat} \mathrm{ile} 576$ araç/saat arasında değişirken, kayıp zaman süreleri 6 sn. ile 15 sn. arasında değişmiştir. 3 fazlı olarak işletilen kavşakta farklı kayıp zaman sürelerinin elde edilmesinde sarı 1şık süresi $1 \mathrm{sn}$. ile $3 \mathrm{sn}$. arasında, her yöne kırmızı 1 şık süresi ise $1 \mathrm{sn}$. ile $2 \mathrm{sn}$. arasında değiştirilmiştir. Böylece 266 farklı trafik durumunu içeren veri seti oluşturulmuş ve her bir trafik durumunun optimum devre süreleri arama algoritması ile belirlenmiştir. Mallipeddi ve diğ. [18] yapmış olduğu çalışma sonucunda DGA'nın parametreleri olan $N P, C R$ ve $F$ için optimum aralık ortaya koymuşlardır. Popülasyon boyutu için $4 D$ ile $10 D$ arasında, çaprazlama oranı için 0,9 ile 1 arasında ve mutasyon katsayısı için 0,4 ile 0,95 arasında olması gerektiğini belirtmişlerdir. Optimum çalışma aralıklarına göre belirlenen kontrol parametreleri Tablo 1'de verilmiştir.

Tablo 1. Diferansiyel Gelişim Algoritması Kontrol Parametreleri

\begin{tabular}{ll}
\hline Popülasyon boyutu $(N P)$ & 30 \\
Çaprazlama oranı $(C R)$ & 0.90 \\
Mutasyon katsayısı $(F)$ & 0.95 \\
Toplam iterasyon sayısı & 2000 \\
\hline
\end{tabular}

266 farklı trafik durum verisi kullanılarak Denklem 8'de verilen Webster optimum devre süresi bağıntısının kalibre edilmiş formu, Webster optimum devre süresi bağıntısına sabit eklenmiş formu ve üstel form olmak üzere 3 farklı model geliştirilmiştir. Model formları Denklem 9-11'de verilmektedir.

$$
\begin{aligned}
& C=\frac{1.5 L+5}{1-Y} \\
& C=\frac{(a L+b)}{(1-c Y)}
\end{aligned}
$$




$$
\begin{aligned}
& C=\frac{(a L+b)}{(1-c Y)}+d \\
& C=a L e^{b Y^{c}}+d
\end{aligned}
$$

ÇTA yaklaşımıyla önerilen model formları optimize edilmiş ve model katsayıları belirlenmiştir. Yang 0,05 ile 0,95 arasında olasılık anahtarının ve 10 ile 50 arasında popülasyon boyutunun kullanılabilir olduğunu göstermiş ve farklı değerlerinin performansını incelemiştir. $N$ için 25 ve $P$ için 0,8 değerlerinin en uygun çalışma durumları olduğunu ifade etmiştir [19]. Kullanılan bu yaklaşımın kontrol parametre değerleri Tablo 2'de sunulmuştur.

Tablo 2. Çiçek Tozlaşma Algoritması Kontrol Parametreleri

\begin{tabular}{lc}
\hline Popülasyon sayısı $(N)$ & 25 \\
Olasılık anahtarı $(P)$ & 0.8 \\
Toplam iterasyon sayısı & 2000 \\
\hline
\end{tabular}

Model katsayılarının belirlenmesinde amaç fonksiyonu ortalama mutlak yüzdesel hataların (OMYH) minimize edilmesi olarak belirlenmiştir. Buna göre, DGA yaklaşımıyla her bir trafik durumu için minimum gecikmeyi veren devre süresi, referans alınan devre süresi olup ÇTA yaklaşımı kullanılarak tahmin edilen optimum devre süreleri arasındaki yüzdesel fark amaç fonksiyonunun değerini vermektedir. Amaç fonksiyonun ifadesi Denklem 12'de verilmiştir.

$$
F(x)=\Sigma\left|\left(\operatorname{Copt}_{D G A}-\operatorname{Copt}_{C, T A}\right) / \operatorname{Copt}_{D G A}\right| * 100
$$

Geliştirilen model formlarının ÇTA yaklaşımı ile optimize edilmesi sonucu belirlenen her modele ait katsayı değerleri Tablo 3'de verilmektedir.

Tablo 3. Model Katsayıları

\begin{tabular}{cccc}
\hline Katsayilar & Model 1 & Model 2 & Model 3 \\
\hline$a$ & 1,59 & 1,60 & 0,51 \\
$b$ & 9,53 & 9,98 & 2,96 \\
$c$ & 0,81 & 0,81 & 1,11 \\
$d$ & & $-0,78$ & 23,17 \\
\hline
\end{tabular}

\section{Bulgular ve Tartışma}

ÇT A yaklaşımına dayalı olarak geliştirilen optimum devre süresi tahmin modelleri ile Webster optimum devre süresi modeli arama algoritmasından elde edilen optimum devre süreleri ile karşılaş̧ırılmış ve değerlendirmelerde ortalama karesel hataların karekökü (OKHK), ortalama mutlak hatalar (OMH) ve belirleme katsayısı $\left(\mathrm{R}^{2}\right)$ performans kriterleri olarak kullanılmıştır. Kullanılan performans kriterlerinin ifadeleri Denklem 13-15'de verilmiştir.

$$
\begin{aligned}
& O K H K=\sqrt{\frac{1}{m} \sum_{n=1}^{m}\left(C_{D G A}-C_{C, T A}\right)^{2}} \\
& O M Y H=\frac{1}{m}\left|\sum_{n=1}^{m}\left(\left(C_{D G A}-C_{C T A}\right) / C_{D G A}\right)\right| * 100 \\
& R^{2}=1-\left[\frac{\sum_{1}^{m}\left(C_{D G A}-C_{C T \text { tatahmin }}\right)^{2}}{\sum_{1}^{m}\left(C_{D G A}-C_{\text {ortalama }}\right)^{2}}\right]
\end{aligned}
$$

Webster, VISTRO ve geliştirilen modellere ait OKHK, OMH ve belirleme $R^{2}$ değerlerinin optimum devre süresine ve gecikmeye bağlı istatiksel sonuçları aşağıda Tablo 4 ve 5'de verilmektedir. 
Tablo 4. Optimum Devre Süresine Bağlı İstatistiki Sonuçlar

\begin{tabular}{cccccc}
\hline & Webster & VISTRO & Model 1 & Model 2 & Model 3 \\
\hline OKHK & 73,37 & 62,49 & 4,48 & 4,47 & 4,19 \\
OYMH & 33,48 & 26,28 & 7,04 & 7,03 & 6,14 \\
$\mathbf{R}^{\mathbf{2}}$ & 0,74 & 0,88 & 0,96 & 0,96 & 0,97 \\
\hline
\end{tabular}

Tablo 5. Gecikmeye Bağlı İstatistiki Sonuçlar

\begin{tabular}{cccccc}
\hline & Webster & VISTRO & Model 1 & Model 2 & Model 3 \\
\hline OKHK & 23,99 & 20,73 & 4,40 & 4,68 & 4,87 \\
OYMH & 20,71 & 18,22 & 6,19 & 7,31 & 6,48 \\
\hline
\end{tabular}

Optimum deve süresine bağlı istatiksel sonuçlara bakıldığı zaman ÇTA kullanarak geliştirilen modellerden Model-3 'ün en düşük OKHK ve OYMH ile en yüksek $\mathrm{R}^{2}$ değeri, en iyi performansa sahip olduğunu göstermektedir. Aynı zamanda Model 3'e göre daha düşük performansa sahip olan diğer 2 modelde Webster optimum devre süresi modeli ve VISTRO optimizasyonuna göre daha iyi performansa sahip olmuştur.

Gecikmeye bağl1 istatistiki sonuçlar incelendiğinde geliştirilen modellerin önermiş olduğu devre sürelerine bağli olarak elde edilen gecikme değerlerinin Webster modeli ve VISTRO optimizasyon devre sürelerinden daha düşük olduğu ve istatistiki sonuçları OKHK ve OYMH değerlerinin daha iyi olduğu görülmektedir. Önerilen 3 modelinde gecikme performanslarına bağlı olarak OKHK değerleri 4.40 ile 4.87 arasında değişirken modellere göre Webster modelinin OKHK değeri yaklaşık 5.5 kat ve VISTRO optimizasyon OKHK değeri yaklaşık 4 kat daha fazla çıkmıştır. Benzer durum OYMH istatistiklerinde de görülmektedir. Bütün bu analizler her 3 modelinde performanslarının Webster modelinden ve VISTRO optimizasyonundan daha iyi olduğunu ve izole sinyalize kavşaklarda optimum devre süresi tahmininde kullanılabileceğini göstermektedir. VISTRO optimizasyon programı ise Webster modelinden daha iyi sonuçlar elde etmiş ve daha düşük gecikme ile devre sürelerini bulabilmiștir.

6, 9, 12 ve 15 sn. kayıp zamanlara ait geliştirilen modellerle Webster modeli ve VISTRO optimizasyon karşılaştırılmasında toplam kritik akım oranına karşılık gelen optimum devre sürelerinin grafiksel gösterimleri ise Şekil 3-6'da verilmektedir. Ayrıca VISSIM simülasyon programı üzerinden elde edilen gecikme değerlerinin grafiksel gösterimi Şekil 7-10'da verilmektedir.

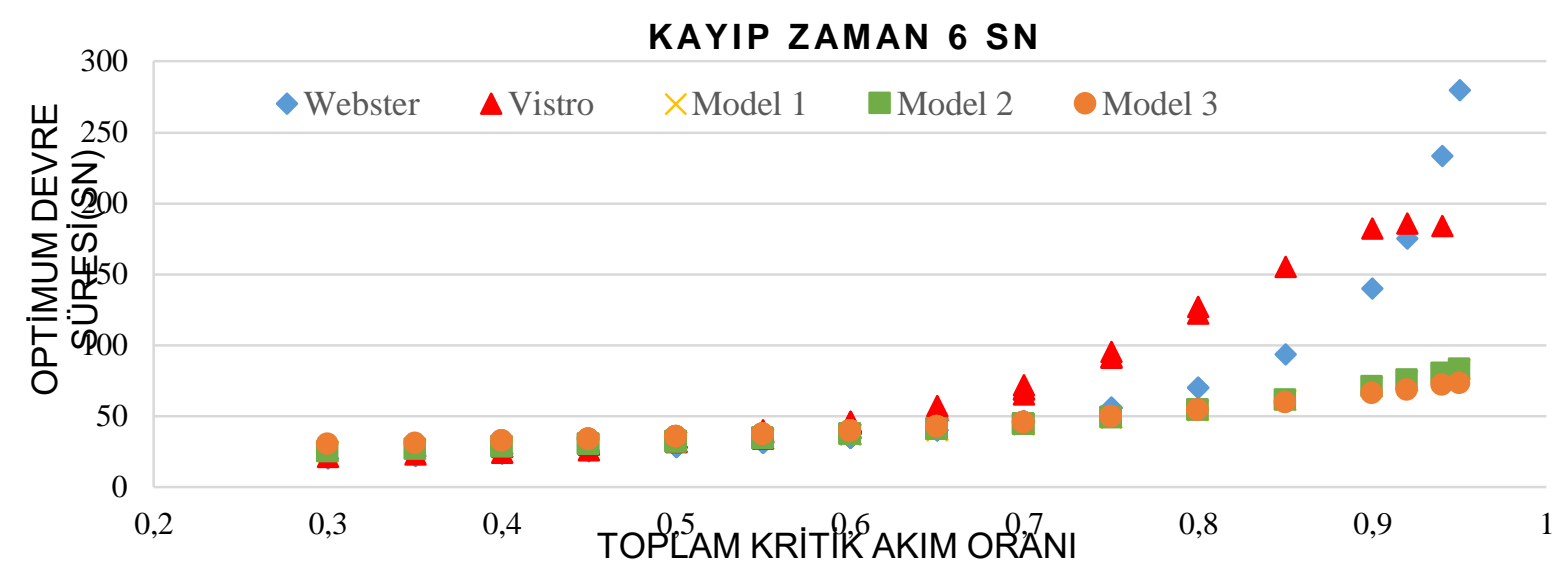

Şekil 3. Kayıp zaman 6 sn için optimum devre süresi değişimi 


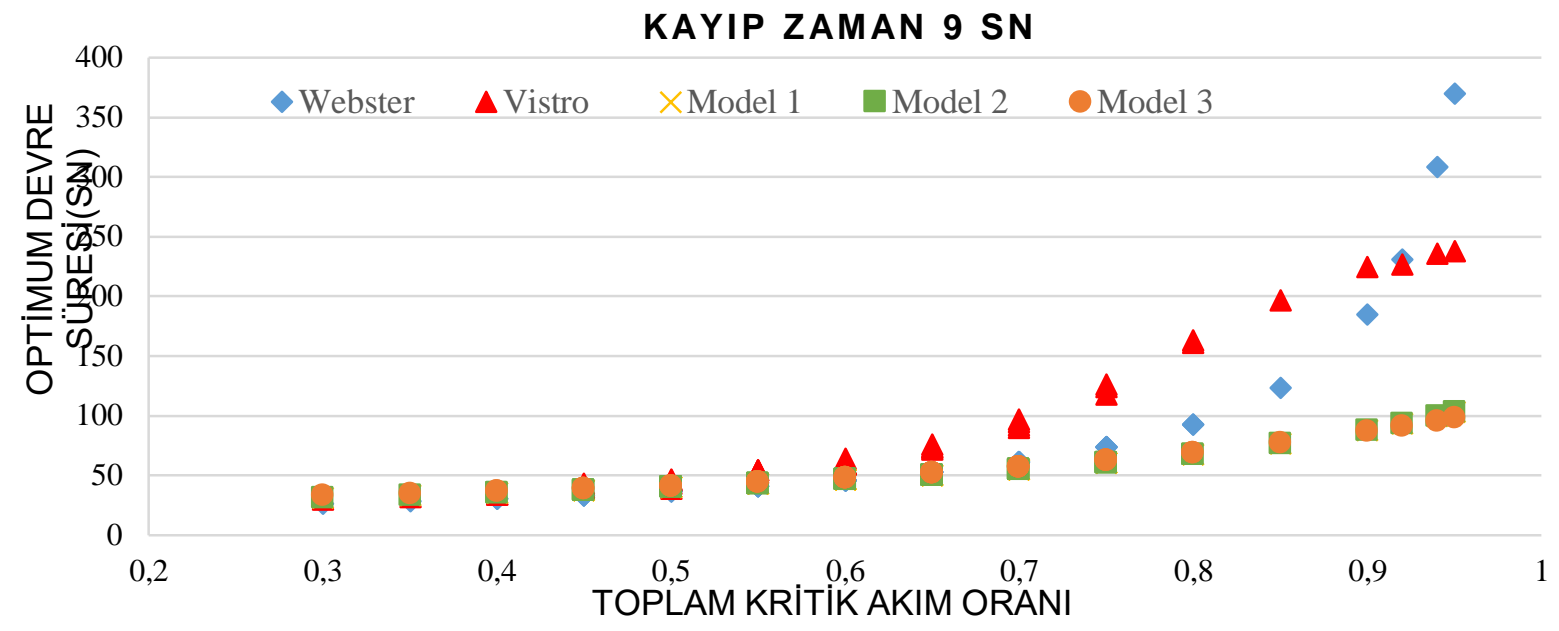

Şekil 4. Kayıp zaman 9 sn için optimum devre süresi değiş̧imi

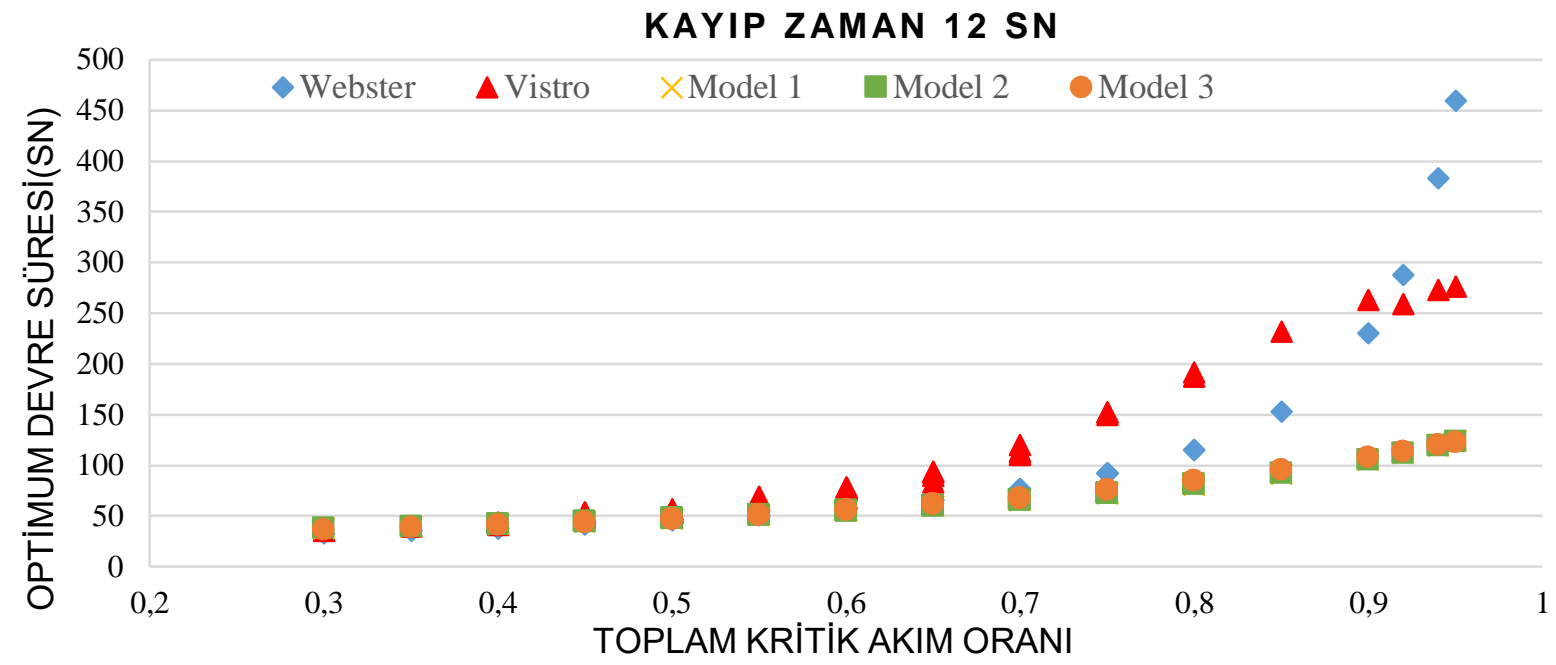

Şekil 5. Kayıp zaman 12 sn için optimum devre süresi değişimi

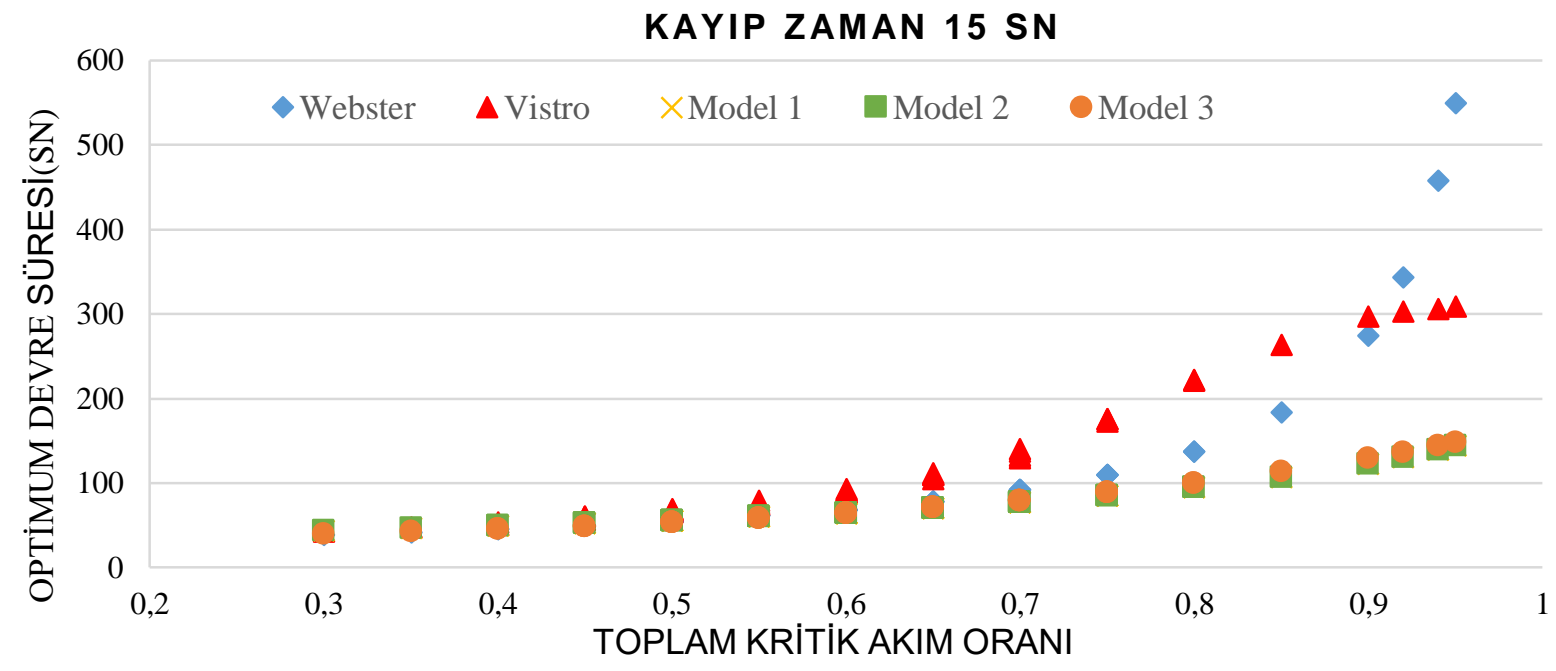

Şekil 6. Kayıp zaman 15 sn için optimum devre süresi değişimi 


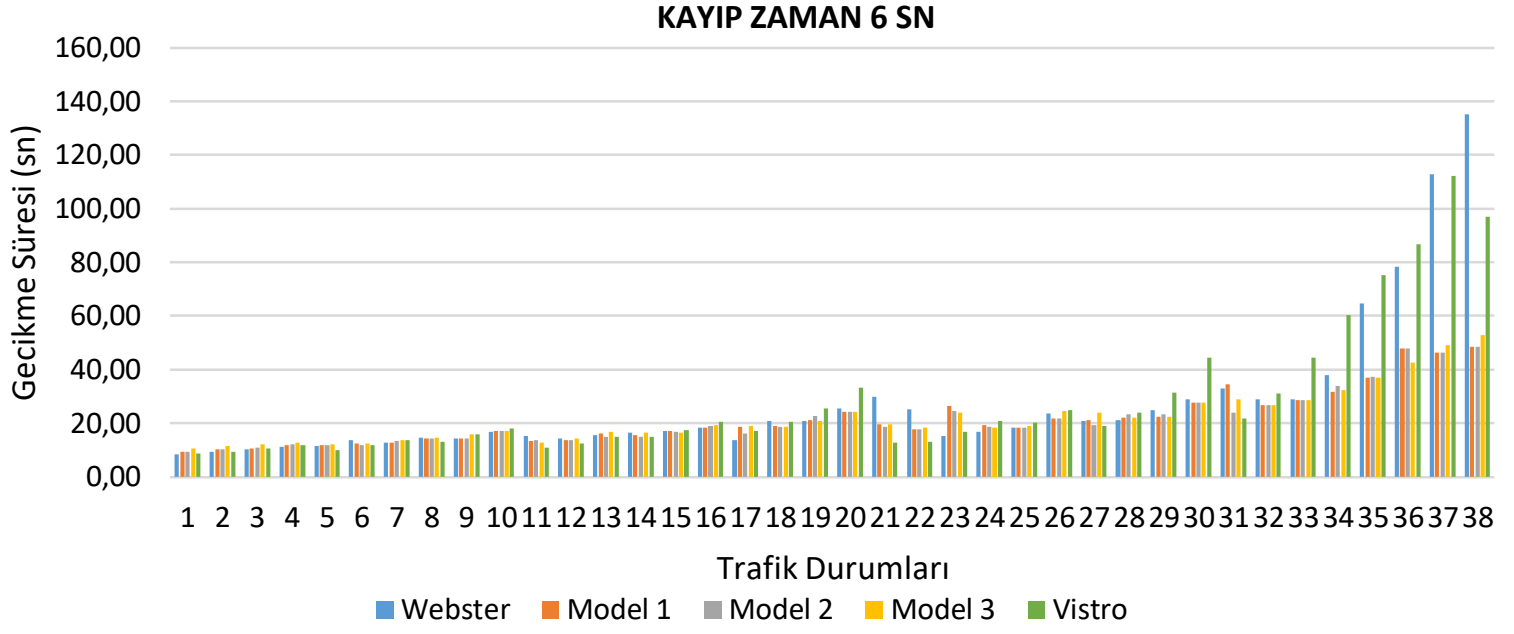

Şekil 7. Kayıp zaman 6 sn için gecikme değerleri

KAYIP ZAMAN 9 SN

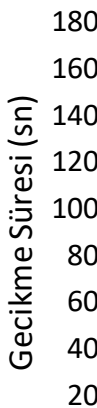

0

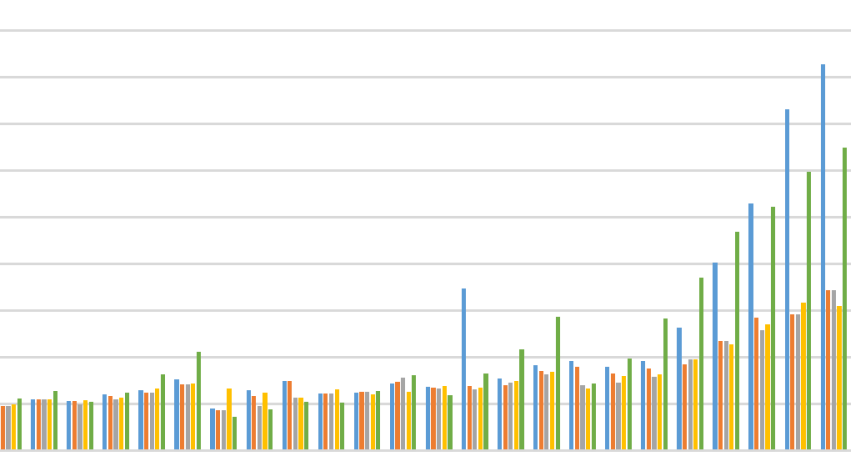

12234456678991011121314151617181920212223242526272829303132333435363738 Trafik Durumları

Webster Model $1 \square$ Model $2 \square$ Model $3 \square$ Vistro

Şekil 8. Kayıp zaman 9 sn için gecikme değerleri

\section{KAYIP ZAMAN 12 SN}

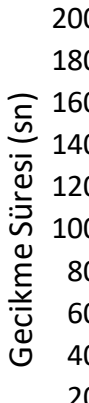

0

$123 \quad 4 \quad 5 \quad 6 \quad 7 \quad 891011121314151617181920212223242526272829303132333435363738$

Trafik Durumları

webster Model $1 \square$ Model $2 \square$ Model $3 \square$ Vistro

Şekil 9. Kayıp zaman 12 sn için gecikme değerleri 


\section{KAYIP ZAMAN 15 SN}

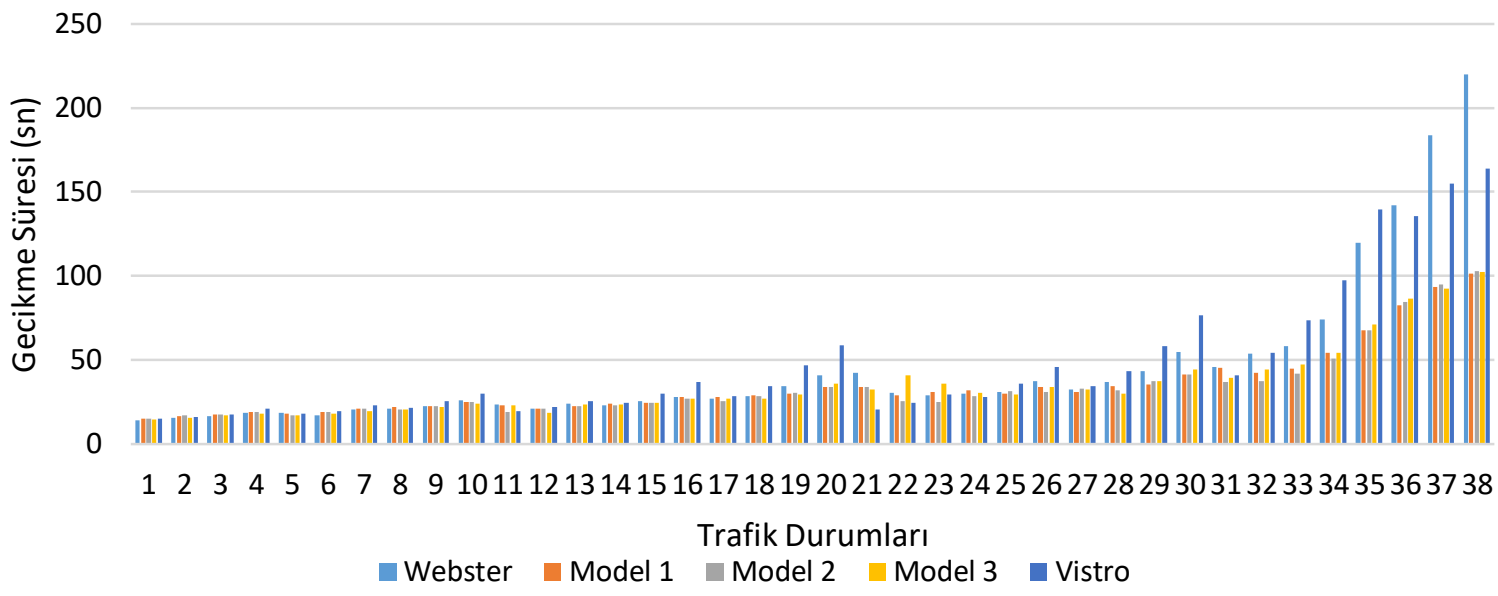

Şekil 10. Kayıp zaman 15 sn için gecikme değerleri

Şekil 3-6 incelendiğinde; kayıp zamanların her bir değeri için toplam kritik akım oranı 0,65 seviyesine kadar Webster modeli ve VISTRO optimizasyonu ile geliştirilen her üç modelin birbirine yakın devre süresi değerleri verdiği görülmektedir. Ancak kritik akım oranı 0,65 ve daha yüksek değerlerde olduğunda Webster modelinin ve VISTRO'nun performansı düşüş göstermekte ve kritik akım oranı 1'e yaklaştıkça bu modeller çok yüksek devre süreleri önermektedir. Geliştirilen modellerse tüm kritik akım oranlarında genel olarak birbirine yakın optimum devre süresi değerleri önermekte olup, Webster modeline ve VISTRO'ya göre daha düşük optimum devre süreleri tahmin etmişlerdir.

Kayıp zamanın artışıla beraber kritik akım oranının 0.65 ve üzeri değerlerinde Webster modeli, VISTRO optimizasyonu ve geliştirilen modellerin verdiği devre süreleri değerlerinde de artış gözlemlenmektedir. Ancak geliştirilen modellerdeki artış Webster'e göre daha az olup bu durum kavşak kollarına gelen trafik hacmindeki artışlarla da ilişkilidir. VISTRO optimizasyonunda kritik akım oranı arttıkça devre süresinde de artış görülmekte olup bu artış lineere yakın şekilde oluşmatakdır. Fakat Webster modelinde akım oranı 0,75 'den sonra devre süresi üstel şekilde artmakta ve daha yüksek devre süreleri tahmin etmektedir.

Şekil 7-10 incelendiğinde; özellikle akım oranının 0,75 ve üzeri değerlerinde Webster modeli ile VISTRO optimizasyonunun Model-1, Model-2 ve Model-3'e göre daha yüksek gecikme değerleri verdiği görülmektedir. Bunun nedeninin VISTRO optimizasyon modülünün izole kavşaklardan ziyade yol ağındaki çoklu kavşak optimizasyonunda devre sürelerinin belirlenmesinde daha etkin olmasından kaynaklandığı düşünülmektedir. VISTRO modolünün ise Webster modelinden daha düşük gecikmelerle ile optimum devre süresini tahmin edebilme kapasitesine sahip olduğu anlaşılmaktadır. Özellikle trafik yoğunluğunun fazla olduğu kavşaklarda geliştirilen modellerin kullanılmasının gecikmeyi düşürmede ve de kavşak performansını arttırmakta daha efektif olacağı istatistiki sonuçlarla ortaya konulmuştur.

\section{Sonuç ve Öneriler}

$\mathrm{Bu}$ çalışma ile farklı yaklaşımların ve model formlarının minimum gecikmeyi veren optimum devre süresi hesabında etkin şekilde kullanılabilir olduğu ve ÇTA yaklaşımı ile daha düşük gecikme değerlerinde kavşak kontrolüne olanak sağlayan devre sürelerinin tahmin edilebilmesinin mümkün olduğu ortaya konulmuştur. Geliştirilen modellerle doygunluk derecesi 1'e yaklaşan trafik durumları için gecikme değerlerinde Webster göre yaklaşık \%50 ve ve VISTRO'ya göre belirgin bir oranda düşüş sağlanabildiği gözlemlenmiştir. Gecikme değerinin düşmesiyle beraber kavşaklarda kapasitenin düşmesi, gereksiz bekleme dolayısıyla da yakıt tüketiminin artması engellenmiş olunacak ve buna bağlı olarak emisyon değerleri düşecektir. Ayrıca sürücülerin trafikteki agrasif davranışlarından kaçınmasına da yardımcı olabilecektir. Çalışmanın temel ilkesi minimum gecikme ile kavşağın yönetilmesini amaç edindiği için yerel yönetimin veya trafik kurumlarının trafik planlamalarında bu çalışmadan çıkacak sonuçlardan planlama, karar alma vb. süreçlerde yararlanabilecekleri düşünülmektedir. Ayrıca optimizasyon yöntemleri her geçen gün gelişmeye devam etmekte ve literatüre yeni yaklaşımlar ile yeni 
algoritmalar katılmaktadır. Farklı algoritmalarında performanslarının incelenmesi ve daha iyi sonuçların elde edilebilmesi için farklı yaklaşımlarında uygulanabilirliği çalışmanın daha ileriye gitmesi açısından önem arz etmektedir.

\section{Teşekkür}

Bu çalışma Kırıkkale Üniversitesi Bilimsel Araştırma Projeleri Komisyon Birimi tarafından (2018/031) nolu BAP projesi ile desteklenmiştir.

\section{Yazarların Katkısı}

Çalışmada Ali Payıdar AKGÜNGÖR fikir, kavram, tasarım, eleştirel inceleme konusunda; Sevim YAVUZ veri toplama, analiz ve yorum konusunda; Ersin KORKMAZ ve Erdem DOĞAN analizlerin incelenmesi, kaynak taraması ve makalenin yazımı konusunda katkı sağlamıştır.

\section{Çıkar Çatışması Beyanı}

Yazarlar arasında herhangi bir çıkar çatışması bulunmamaktadır.

\section{Araştırma ve Yayın Etiği Beyanı}

Yapılan çalışmada araştırma ve yayın etiğine uyulmuştur.

\section{Kaynaklar}

[1] Webster F.V. 1958. Traffic signal settings, road research technical paper. No: 39, Road Research Laboratory.

[2] Thomas G.B., Upchurch J.E. 1998. Effect of non-optimal cycle lengths and traffic volumes on progression. Institute of Transportation Engineers. ITE Journal, 68 (5): 38.

[3] Lan C.J. 2004. New optimal cycle length formulation for pretimed signals at isolated intersections. Journal of Transportation Engineering, 130 (5): 637-647.

[4] Cheng D., Tian Z.Z., Messer C. J. 2005. Development of an improved cycle length model over the highway capacity manual 2000 quick estimation method. Journal of Transportation Engineering, 131 (12): 890-897.

[5] Day C., Bullock D., Sturdevant J. 2009. Cycle-length performance measures: revisiting and extending fundamentals. Transportation Research Record: Journal of the Transportation Research Board, (2128): 48-57.

[6] Singh L., Tripathi S., Arora H. 2009. Time optimization for traffic signal control using genetic algorithm. International Journal of Recent Trends in Engineering, 2 (2): 4-6.

[7] Al-Kubaisi M.I. 2012. Optimum Cycle Time Prediction for Signalized Intersections at Baghdad City. Cankaya University Journal of Science and Engineering, 9 (2): 149-166.

[8] Sun S.N., Xiao W., Qiu X., Chen J.D., Ying L.X. 2012. Design and Simulation of Urban Road Intersection Signal Linear Control System. In: Applied Mechanics and Materials, 178: 27132716.

[9] Dai L.L., Sun Z.L., Liu D.B., Li Y. 2013. An Improved Method of Traffic Control Period Division for Intersection Based on Signal Cycle Calculation. In Applied Mechanics and Materials 253: 1731-1735.

[10] Dell'Orco M., Baskan O., Marinelli M. 2013. A Harmony Search Algorithm approach for optimizing traffic signal timings. PROMET-Traffic \& Transportation, 25 (4): 349-358.

[11] Wu Y., Lu J., Chen H., Yang H. 2015. Development of an optimization traffic signal cycle length model for signalized intersections in China. Mathematical Problems in Engineering, 954295: 19.

[12] Çakıcı Z., Murat Y.Ş. 2015. Sezgisel Optimizasyon Algoritmalarının Taşıt Gecikmesi Problemi Üzerine Uygulamas1.7. Kentsel Altyap1 Sempozyumu, Trabzon, 615-625. 
[13] Zakariya A.Y., Rabia S.I. 2016. Estimating the minimum delay optimal cycle length based on a time-dependent delay formula. Alexandria Engineering Journal, 55 (3): 2509-2514.

[14] Jovanović A., Nikolić M., Teodorović D. 2017. Area-wide urban traffic control: A Bee Colony Optimization approach. Transportation Research Part C: Emerging Technologies, 77: 329-350.

[15] Storn R., Price K. 1997. Differential evolution-a simple and efficient heuristic for global optimization over continuous spaces. Journal of global optimization, 11 (4): 341-359.

[16] Yang X.-S. 2014. Nature-inspired optimization algorithms. Elsevier.

[17] http://vision-traffic.ptvgroup.com/en-us/products/ptv-vissim/use-cases/ (Erişim Tarihi: 15.04.2019).

[18] Mallipeddi R., Suganthan P.N., Pan Q.-K., Tasgetiren M.F. 2011. Differential evolution algorithm with ensemble of parameters and mutation strategies. Appl. Soft Comput., 11 (2): 1679-1696.

[19] Yang X.-S. 2012. Flower pollination algorithm for global optimization. In: International conference on unconventional computing and natural computation, 240-249. 